\title{
Secondary predication and the distribution of raising to object
}

\author{
Marcel den Dikken \\ Eötvös Loránd University, Budapest; \\ Research Institute for Linguistics \\ Hungarian Academy of Sciences \\ marcel.den.dikken@nytud.mta.hu
}

\begin{abstract}
In Den Dikken (2017b) arguments are presented for a predicational approach to hyperraising and copy raising constructions in which the 'raised' DP serves as the subject of the matrix clause. In this sequel, I show that hyperraising and copy raising also occur in secondary predication constructions embedded under propositional attitude verbs such as consider. An examination of the properties of these hyperraising and copy raising to object constructions leads to the conclusion that overt subject-toobject raising ('object shift') definitely exists in English but is obligatory only for subjects of small-clause complements of verbs. Apart from yielding a clearer perspective on the distribution of overt object shift in English, the study also delivers a unified account of a variety of restrictions on the subject of the non-finite complement of propositional attitude verbs.
\end{abstract}

Keywords: copy raising; raising to object; ECM; predication; subject

\section{Hyperraising and copy raising - to subject and to object}

Examples of hyperraising and copy raising familiar from the literature (Ferreira 2000; 2004; Martins \& Nunes 2006; Nunes 2008, for hyperraising in Brazilian Portuguese, and Halpert 2016 for hyperraising in Bantu and beyond; Potsdam \& Runner 2001; Asudeh \& Toivonen 2012, i.a., for copy raising in English) consistently feature the raised DP as the subject of the matrix clause. The examples in (1) (from Brazilian Portuguese) and (2) illustrate the familiar patterns.

(1) os meninos parecem que estão doentes the.PL children seem.3PL that be.3PL sick.PL 'the children seem to be sick'

(2) the children seem $\{$ like/as if/as though $\}$ they're sick

Already in Kuno (1976), it was pointed out (in the wake of Postal's 1974 study of raising phenomena) that in Japanese, raising-to-object seems to 
be able to proceed across a finite clause boundary - or, put differently (in terms that were not in vogue yet at the time), that Japanese allows hyperraising to object. A typical example is reproduced in (3).

(3) Yamada-wa Tanaka- $\{$ ga/o $\}$ baka da to omotteita

Yamada-TOP Tanaka-NOM/ACC fool is COMP thought

'Yamada thought Tanaka was/to be a fool.'

With nominative Tanaka-ga, (3) is a garden-variety case of finite clausal complementation, with the nominative DP as the subject of the subordinate clause. Interestingly, however, it is also possible for Tanaka, the logical subject of the lower clause, to be marked with the accusative case particle - $o$. Kuno shows that when Tanaka is adorned with -o, it behaves in just about all imaginable respects like the object of the matrix clause: ${ }^{1}$

(4) a. Yamada-wa Tanaka- $\left\{{ }^{*}\right.$ ga $/{ }^{\vee}$ o $\}$ orokanimo baka da to omotteita Yamada-TOP Tanaka-NOM/ACC stupidly fool is COMP thought 'Yamada stupidly thought that Tanaka was a fool.'

b. Tanaka- $\left\{*^{*}\right.$ ga $/{ }^{\vee}$ o $\}$ Yamada-wa baka da to omotteita Tanaka-NOM/ACC Yamada-TOP fool is COMP thought 'Tanaka Yamada thought to be a fool.'

c. dareka-ga minna- $\{\mathrm{ga} / \mathrm{o}\}$ baka da to omotteiru someone-NOM all-NOM/ACC fool is COMP thinks with -ga: $\quad \exists>\forall \quad * \forall>\exists \quad \underline{\text { with - } O:} \quad \exists>\forall \quad(?) \forall>\exists$

d. Yamada ${ }^{-w a}$ kare $_{i}-\left\{{ }^{\checkmark}\right.$ ga $/ *$ o $\}$ baka da to omotteita Yamada-TOP he-NOM/ACC fool is COMP thought 'Yamada $i$ thought he ${ }_{i}$ was/to be a fool.'

${ }^{1}$ The only respect in which Tanaka-o is not a typical matrix object, according to Kuno, is its behaviour under passivisation: Kuno points out that the raised accusative cannot be promoted to matrix subject in a simple passive (though such promotion does work in an adversative passive). I will leave this aside, noting in general that it is not the case that any and all accusative objects can be promoted to subject in passive sentences: there are restrictions on passivisation which cause it to undergenerate under particular circumstances (often not perfectly understood). Especially relevant in the context of raising to object is the fact that Accusativus-cum-Infinitivo constructions involving bare infinitives in the complement of verba sentiendi and causative verbs quite generally resist passivisation in Germanic (they saw/made him eat the cake vs. *he was seen/made eat the cake; the fact that insertion of to renders the latter grammatical is an English-specific strategy which has not yielded to analytical consensus in the literature). 
As (4a) shows, when the embedded subject is adorned with - $o$ it can show up to the left of adverbial material that unambiguously belongs to the matrix clause. In (4b) we see that it can also scramble to the left edge of the matrix clause, on a par with objects. For (4c), the predominant reading for the version with the -o marked subject is the same as that for the one with minna-ga; but unlike nominative minna-ga, accusative minna-o can also take scope over the matrix subject, in the same way and to the same extent that a matrix object can take inverse scope. From (4d) it emerges that it is impossible to replace Tanaka-o in (3) with a pronoun coindexed with the matrix subject - a straightforward Principle B effect with kare-o situated in the matrix clause.

For copy raising (the phenomenon illustrated in (2), where the 'raised' $\mathrm{DP}$ is linked to a copy pronoun in the subordinate clause), no cases have been reported, to my knowledge, in which the matrix object position is implicated. It turns out, however, that such cases can be found quite easily in colloquial English. Below is a sample of copy raising to object examples, all culled from the internet with the help of a Google search (for strings such as 'consider him like he'), for three established raising to object predicates, regard, consider and make out (on this last case, see esp. Kayne 1985, and also Johnson 1991): ${ }^{2}$

${ }^{2}$ Also in this set may be view, judge and rate. In the case of regard, some care is needed with the attestations of the regard ACC like NOM ... pattern: after all, the accusative following regard could potentially be the thematic object of the verb (as in I regard him highly). Thus, for a string such as they regard him like he is a genius, we may very well be dealing with a syntax in which him is the verb's object, and the like-phrase is an adjunct (cf. they regard him highly, like/as if he is a genius). For the examples in (6), such a construal is highly improbable, given the nature of the predicate following like.

I have not undertaken any comparative research on the spread of copy raising to object within Germanic. It appears that it is possible in Dutch, judging from attested examples such as those in (i) (of which (ia) is from the novel De beproeving by Doeschka Meising). Note that unlike English regard, Dutch beschouwen cannot take a nominal object. Though I am not an avid copy raiser in general, the cases of the type in (i) that I have seen sound acceptable to my native Dutch ear.

(i) a. ik beschouw hem alsof hij alleen voor mij geschreven is

I consider him as.if he only for me written is

'I regard it (i.e., a symphony by Haydn) like it was written just for me.'

b. beschouw ze alsof ze al opgelost zijn

consider them as.if they already solved are

'regard them like they have already been solved' 
(5) consider ACC like NOM ...

a. Trump isn't even in office and people consider him like he is Jesus

b. a lot of them just consider him like he wasn't definitely much more than a 'character'

c. we still consider him like he's a rookie

d. you have to basically consider him like he's still a freshman in the NCAA

e. the few female friends that I have just consider me like I was one of their female friends

f. we may not be related, but many of our clients consider us like we're family

g. I don't see how our parents can consider us like we're related family

(6) regard ACC like NOM ...

a. they regard me like I'm some sort of thief

b. she began to regard me like I was less of a person, less important, less trustworthy, less reliable, less real even

c. you regard me like I am some stranger, something foreign, alien, un-comely

d. we have done nothing wrong yet people in the wind industry and local and national government appear to regard us like we are the offenders

e. they always regard them like they are less than real people

f. if you regard them like they are not worth your salary, they are even more lost

g. thus, discovering that your kid has dyslexia or ADHD doesn't mean you need to regard them like they're not as savvy as an 'ordinary' child

(7) make ACC out like NOM ...

a. some people make him out like he's the best

b. she made him out like he was some sex abuser

c. Leftys made him out like he was such a hero

d. I just don't understand why people made him out like he's super scum or anything

e. they tried to make us out like we were shit

f. they make me out like I'm a sinister person

g. I feel ashamed when I look in the paper as the police are trying to make me out like I am a monster and a bully when I am not

For the verb+preposition combinations look upon and think of, known to embed as+gerund (John looks upon/thinks of Mary as having talent), we also find this copy raising pattern: ${ }^{3}$

${ }^{3}$ Also in this set may be look at and listen to. Both (8)-(9) and their more familiar counterparts featuring as+gerund raise the non-trivial question of how the noun 
(8) look upon ACC like NOM ...

a. these people look upon us like we are scum

b. the crowd will look upon us like we are freaks they look upon us like we shouldn't be doing these things

c. those people at the embassy, they only look upon us like we are mice

d. please don't look upon us like we're all a bunch of ignorant racists

e. they just look upon us like we're a nuisance

f. you look upon us like we're pets

(9) think of ACC like NOM ...

a. if you want, we can think of him like he's our dog

b. I think of him like he's my brother

c. they think of him like he's one of us

d. we both think of him like he's our son

e. I think of them like they are spam

f. you will think of us like we are a close friend

g. people think of us like we're an endless, filthy army of people hopping a border like we're thirsty for American blood

These copy raising constructions passivise just like their counterparts with non-finite complement clauses do. In (10), I include some relevant cases found on the web, for look upon (which is the easiest to passivise, in the colloquial register in which the copy raising construction is found):

(10) a. he is looked upon like he is a douche by other heroes

b. he is looked upon like he is the greatest QB in league

c. he is looked upon like he is someone's likable but slightly goofy uncle at a party

These passive examples are very similar to the copy raising to subject examples in (11), featuring strike, which, like regard, look upon and think of, combines with as+gerund (as in she strikes me as having talent) or like+finite clause:

phrase following the preposition (upon, of) can serve as a subject of predication (cf. * John ate at/of the meat raw). The ungrammaticality of *the analysis upon which $I$ look as (being) inadequate indicates that upon does not form a constituent with the following noun phrase; that of *upon you as (being) stupid, I don't look suggests that the string from upon down to the secondary predicate is not a constituent either. For want of a better solution, I will treat look upon and think of as complex verbs: this will account for the previous observations about constituency, and will also allow for the noun phrase following upon/of to serve as a subject of predication. 
(11) a. he strikes me like he needs a friend

b. she strikes me like she'll develop into a real stayer in time

c. they strike me like they're trying too bloody hard on the field

For all of the sentences in (1)-(9), an analysis in terms of raising ('NP-movement') requires major departures from standard constraints on movement. Non- $\bar{A}$-movement does not normally proceed out of finite clauses. Moreover, resumptive pronouns have a very restricted distribution in chain formation contexts. For the examples in (3)-(9), this paper proposes an analysis according to which these are secondary predication constructions with the accusative as the subject of a predicate defined as such thanks to the fact that it contains what Williams (1980) calls a predicate variable - a pronoun (silent or overt) linked to the matrix accusative. No NP-movement is involved in the derivation of any of these sentences. We will see that this analysis derives the properties of hyperraising and copy raising to object constructions accurately, and has important consequences for the syntax of raising to object.

\section{Predication and secondary predication}

In Den Dikken (2017b), an analysis for (1) and (2) is proposed in which the subject of the matrix clause originates in that clause, its predicate being formed thanks to the fact that the matrix subject binds a pronoun in the lower clause as a bound variable:

(12) [RP SUBJECt $i$ [RELATOR [CP C [TP PRONOUn $i$...]]]]

In colloquial English (2), the RELATOR of the predication relation is spelled out as like; in Brazilian Portuguese (1), it remains silent.

(13) [seem [RP the children ${ }_{i}$ [RELATOR=like [CP they ${ }_{i}$ are sick]]]]

The predication structure in (12) serves as the primary predication of a semi-copular clause in the familiar hyperraising and copy raising examples in (1) and (2). But predication structures can be embedded in the complement of a 'real' verb as well, as 'small clauses'. It is my contention that in the examples in (3)-(9), this is precisely what we are dealing with. For the examples involving a finite complement clause, this delivers (14) as their structure:

(14) $\left[\mathrm{V}=\{\right.$ think/consider $/$ regard $/ \ldots\}\left[\mathrm{RP} \mathrm{John}_{i}\right.$ [RELATOR $=$ like $\left[\mathrm{CP}\right.$ he ${ }_{i}$ is a fool] $\left.\left.]\right]\right]$ 
In both (13) and (14), the subordinate CP qualifies as a predicate thanks to the fact that the pronoun inside it is a bound variable (Williams' 1980 'predicate variable'). For (13), Den Dikken (2017b) confirms the bound variable status of the pronoun in the lower clause on the basis of the obligatory sloppy identity reading assigned to ellipsis constructions such as John seems like he's sick, and Sue does, too. The sloppy identity test is not available in the case of copy raising to object (because of independent restrictions on ellipsis: predicates of small clauses do not undergo it - *they regard John as smart, and they regard Sue as smart, too). But we can support the bound variable status of the pronoun inside the lower $\mathrm{CP}$ in sentences of the type in (5)-(9) on the basis of the fact that they only consider/regard/think of me like I'm smart is interpreted as 'for no $x$ besides me do they think that $x$ is smart'.

The idea that the finite CP in the examples in (3)-(9) is the predicate of the accusative in the matrix clause is perhaps most directly confirmed by the systematic parallels between these examples and their counterparts with small clauses regarding restrictions imposed on the predicate. While in the hyperraising and copy raising examples in (1) and (2) the predicate is stage-level (doente, sick), in the examples in (3)-(9) as a rule we find individual-level predicates (such as a fool in the representation in (14)). Kuno $(1976,33)$ states that in the Japanese construction illustrated in (3), the predicate of the embedded clause must be adjectival or nominal. Horn (2008) points out that this is not quite accurate: more specifically, the predicate must usually be an individual-level predicate, denoting a permanent state. ${ }^{4}$ Similarly, in the colloquial English copy raising to object cases, the predicate is usually adjectival or nominal, and in the examples that I have come across it is always individual-level. The sentence in (8c) is not at variance with this: though shouldn't be doing these things is not adjectival/ nominal, it is a modal predicate that is non-episodic and individual-level.

The interest of these observations about the predicate of the embedded finite clause in (3)-(9) lies in the fact that the same predicate restriction is in force in cases of small-clause complementation involving verbs such as consider. Of the adjectival predicates used in (15) and (16), smart and stupid are inherently individual-level, while and $i l l$ and nude are stage-level

${ }^{4}$ Horn (2008) notes that a characterisation of the set of eligible predicates as 'individual-level' (in the familiar sense of Carlson 1977) 'comes closer to observational adequacy than any other proposed in the literature', but still does not quite hit the mark. For our purposes in this paper, however, the precise characterisation of the restriction on the embedded clause's predicate in (3) will not be essential; 'individual-level' comes sufficiently close. 
and therefore unusable in these sentences. The adjective sick is usually a stage-level predicate as well, which is why (15) and (16) are awkward with sick unless it is interpreted as 'mentally ill', in which case sick has an individual-level interpretation, which makes it eligible for participation in these secondary predication constructions.

(15) a. I consider him $\left\{\right.$ smart $/$ stupid $/{ }^{\#}$ sick $/{ }^{*}$ ill $/{ }^{*}$ nude $\}$

b. I regard him as $\left\{\right.$ smart $/$ stupid $/{ }^{\#}$ sick $/ *^{*}$ ill $/{ }^{*}$ nude $\}$

c. I look upon him as $\left\{\right.$ smart $/$ stupid $/{ }^{*}$ sick $/ *^{*}$ ill $/ *^{*}$ nude $\}$

d. I think of him as $\left\{\right.$ smart $/$ stupid $/{ }^{*}$ sick $/ *^{*}$ ill $/ *^{*}$ nude $\}$

(16) a. I consider him like he's $\left\{\right.$ smart/stupid/ ${ }^{\#}$ sick/*ill/*nude

b. I regard him like he's $\left\{\right.$ smart/stupid/ $/{ }^{\#}$ sick $/ *$ ill $/ *^{*}$ nude $\}$

c. I look upon him like he's $\left\{\right.$ smart/stupid $/{ }^{\#}$ sick $/ *^{*}$ ill $/{ }^{*}$ nude $\}$

d. I think of him like he's $\left\{\right.$ smart/stupid $/{ }^{*}$ sick $/ *^{*}$ ill $/ *^{*}$ nude $\}$

It is not the case, of course, that secondary predication in general is possible only with individual-level predicates. In fact, a large class of secondary predication constructions is characterised precisely by the fact that only stage-level predicates participate in it: depictive secondary predication excludes all individual-level predicates, and thus gives rise to a pattern exactly opposite to the one seen (15) and (16).

(17) he left the house $\left\{{ }^{*}\right.$ smart $/ *_{\text {stupid/sick/ill/nude }\}}$

The generalisation that interests me here is that secondary predication in the complement of epistemic verbs requires an individual-level predicate. It is this generalisation that recommends a treatment of the examples in (3)-(9) in terms of secondary predication, with the accusative serving as the subject of a predicate that denotes an individual-level property. The force of this point can best be appreciated by looking at the triples in (18) and (19):

(18) a. I think that he is $\{$ smart/stupid/sick/ill/nude\}

b. I think of him as $\left\{\right.$ smart $/$ stupid $/{ }^{*}$ sick $/ *^{*}$ ill $/{ }^{*}$ nude $\}$

c. I think of him like he's $\left\{\right.$ smart/stupid $/{ }^{*}$ sick $/ *$ ill $/ *$ nude $\}$

(19) a. I made out that he was $\{$ smart/stupid/sick/ill/nude $\}$

b. I made him out to be $\left\{\right.$ smart/stupid/\# $/{ }^{*}$ sick $/ *$ ill $/ *$ nude $\}$

c. I made him out like he was $\left\{\right.$ smart $/$ stupid $/{ }^{*}$ sick $/ *^{*}$ ill $/ *^{*}$ nude $\}$ 
There is nothing about think or make out that requires that there be an individual-level predicate in the clause that it embeds: (18a) and (19a) are grammatical for any choice of predicate. But as soon as think or make out takes a small clause (a RELATOR phrase) as its complement, its predicate can only be individual-level. For our purposes here, deriving this restriction will not be necessary; what counts is that it is a restriction on secondary predication directly in the complement of epistemic verbs. It is this that tells us that the accusative in the examples in (3)-(9) must be treated as the subject of a predication structure. And this, in turn, tells us that the accusative originates in the matrix clause, and that in the hyperraising and copy raising cases in (3)-(9) it is the finite subordinate clause that serves as its predicate.

\section{On expletives and idiom chunks in raising-to-object constructions}

In both Brazilian Portuguese hyperraising constructions such as (1) and colloquial English copy raising constructions of the type in (2), it is possible to fill the matrix subject position with an idiom chunk. For Brazilian Portuguese this is illustrated in (20) (Martins \& Nunes 2006):

(20) o pau parece que comeu feio

the stick seems that ate ugly

'it seems that there was a big discussion/fight'

For English copy raising we see it in (21) (Potsdam \& Runner 2001, 3; Asudeh \& Toivonen 2012): ${ }^{5}$

(21) a. the cat seems like it is out of the bag

b. the shit seems/looks like it could hit the fan any moment now

c. advantage seems like it was taken of the workers

Potsdam and Runner (2001) point out that 'expletive' there can also occur as the subject of copy raising constructions:

${ }^{5}$ Idiom chunk connectivity is also seen in Bantu hyperraising (see Zeller 2006 on Zulu). For Kikuyu, Yuan (2016) argues that its hyperraising constructions must involve movement (not base-generation cum predication), drawing an explicit contrast with copy raising. This contrast seems real and significant. The point of my paper is not to rule out categorically the possibility of A-movement out of (certain, structurally deficient) finite clauses; rather, my point is that for languages such as Brazilian Portuguese and English, a predicational analysis is what is needed. 
(22) there seems like there is going to be a riot

These data can be accommodated in the predication-based approach taken in Den Dikken (2017b). The idiom chunks in (20) and (21) serve as subjects of predication to a predicate containing a bound variable linked to the idiom chunk, just as in tough-movement constructions (advantage is easy to take of her). And although on an analysis of there in (22) as an expletive it would be tough to make sense of the grammaticality of this sentence on a predicational approach, Williams' $(1994 ; 2006)$ treatment of there as a subject of predication can fold (22) right into the analysis of copy raising advocated in Den Dikken (2017b).

When we now look at the raising-to-object versions of hyperraising and copy raising under investigation here, we find that neither idiom chunks nor 'expletive' there can occur in them:

(23) a. *they consider advantage like it's been taken of her

b. *they regard advantage like it's been taken of her

c. *they made advantage out like it's been taken of her

(24) a. *they consider there like there's a problem with the analysis

b. *they regard there like there's a problem with the analysis

c. *they made there out like there's a problem with the analysis

The corresponding 'ECM' constructions in (25)-(26) are grammatical for the a-cases, though as Postal $(1974,242)$ and Kayne $(1985,114)$ point out, resp., not for the b- and c-cases: ${ }^{6}$

${ }^{6}$ Postal (1974, 242): 'By and large, "empty" NPs like existential there, idiom chunks [...] cannot occur in the pre-as position.' In the same vein, Chomsky $(1981,109)$ calls his examples in (i) and (ii) 'relatively unacceptable'. But note that Pollard and Sag (1994, 108) give we regard there as being no solution to this problem as grammatical.

(i) I regard too much as having been made of his failure

(ii) I regard there as being many reasons to continue with our efforts

Johnson (1991), while endorsing Kayne's (1985) judgements regarding his make out cases, points out that ' $[\mathrm{t}$ ] hese judgements do seem to be sensitive to vague semantic factors', presenting I made there out to be a unicorn in the garden as perfectly acceptable to his ear. Similarly, Postal (2004) gives Helen made there out to be seven gorillas in the clearing as grammatical, and professes to finding it remarkable that no defence of Chomsky's 'ECM' analysis seems to have ever addressed this datum. The variation in the judgements is puzzling. It suggests that there are factors involved that are subtler than anything a straight syntax approach can be expected to handle. Neither Johnson nor I can offer any deeper insight into this matter. 
(25) a. they consider advantage to have been taken of her

b. *they regard advantage as having been taken of her

c. *they made advantage out to have been taken of her

(26) a. they consider there to be a problem with the analysis

b. *they regard there as being a problem with the analysis

c. *they made there out to be a problem with the analysis

In the grammatical sentences in (25a) and (26a), the idiom chunk subject or the 'expletive' there is in the structural subject position (SpecIP) of a clause. This position is not the one occupied by the idiom chunk or there in any of the ungrammatical examples in (23)-(26). In Den Dikken (2006) (see also Aarts 1992), as in regard as constructions is treated as the exponent of the RELATOR head in the verb's complement. The particle out in make out constructions is likewise treated plausibly as the lexicalisation of a RELATOR. The element like occurring in sentences of the type in (2), (5)-(11), and (23)-(24) I had also placed in the RELATOR position in Den Dikken (2017b). ${ }^{7}$ Apparently, there is a contrast between structural subject positions (i.e., SpecIP) and 'other' subject positions with regard to occupancy by idiom chunk subjects or there.

There are three indications that suggest that reference to the contrast between structural subjects and 'other' subjects is indeed essential in the context at hand. One is that passivisation of the b- and c-sentences in (25)-(26), which promotes the idiom chunk or there to structural subject of the matrix clause, renders them much better:

${ }^{7}$ In the examples in (7), out and like co-occur, raising the question of competition for the single RELATOR slot in the structure. Though Kayne (1985) notes that they

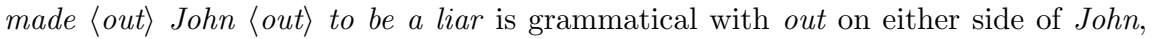
the copy raising construction with make out does not seem to show this flexibility: while strings of the type make DP out like he ... occur readily (e.g., to make the President out like he's some corporate fat cat or some inheritance baby is stupid), the string make out DP like he ... is virtually non-existent. Assuming that the latter is ungrammatical (on a par with the version of they made $\left\langle{ }^{*}\right.$ out $\rangle$ John $\langle$ out $\rangle$ a liar in which the particle is positioned to the left of John; Kayne 1985), I will tentatively accommodate the co-occurrence of out and like in (7) by placing both the particle and like in the RELATOR position. (A reviewer suggests the alternative of RELATOR phrase recursion, with out in the higher RELATOR and like in the lower one, and the accusative raising from the specifier of the lower RP to the specifier of the higher one. This strikes me as implausible in light of the fundamental function of the RELATOR in the sense of Den Dikken (2006), as a mediator of a predication relation: in (7), below make, we have just a single predication relation between the accusative and the clause following like.) 
$\left(25^{\prime}\right)$ a. advantage is considered to have been taken of her

b. ?advantage is regarded as having been taken of her

c. advantage was made out to have been taken of her

$\left(26^{\prime}\right)$ a. there is considered to be a problem with the analysis

b. 'there is regarded as being a problem with the analysis

c. there was made out to be a problem with the analysis

The second is that even under consider (which was found to be more liberal than regard and make out in (25) and (26)), idiom chunk subjects and there do not always flourish. Consider the examples in (27) and (28).

(27) they consider advantage ?? (to be) unlikely to be taken of her

(28) they consider there ?? (to be) unlikely to be a problem with the analysis

Without the parenthesised to be, these sentences are awkward: the strings consider advantage unlikely to... and consider there unlikely to... are quite marginal. ${ }^{8}$

The third indication that idiom chunk subjects and there are generally unhappy in positions that cannot be classified as SpecIP comes from withabsolute constructions:

$(29)^{\text {? }}$ with advantage unlikely to be taken of her, special protection will not be necessary

$(30)$ ? with there unlikely to be a problem with the analysis, we can proceed along this path

${ }^{8}$ Postal $(1974,195)$ admits as much when he points out that ${ }^{?}$ I consider there unlikely to be further violence is possible only 'with a bit of strain'. For idiom chunk subjects, Postal (ibid., fn. 7) says that they 'work the same way' as there, though he presents $I$ consider real advantage unlikely to be taken of that offer without any diacritics that suggest marginality. The severity of the degradation incurred by examples of the type in (27) and (28) (without the parenthesised to be included) is apparently somewhat variable; recall also the previous footnote.

Note that in judging cases of the type in (27) and (28), it is important to use unlikely rather than its positive counterpart, likely. The reason is that likely does not just occur as a raising adjective: it also admits of an adverbial distribution (as

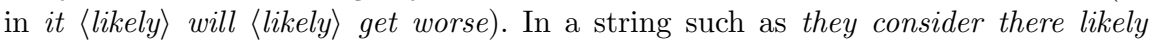
to be problems, which is quite acceptable, it is very difficult (perhaps impossible) to tell whether likely is construed as a raising adjective or instead adverbially (cf. there likely will be problems). For unlikely, this confound does not present itself (or at least, not as prominently): unlikely is not (easily) used adverbially $\left({ }^{*}\right.$ it unlikely will get worse, *there unlikely will be problems). (It may be that some of the speaker variation regarding the severity of the degradation of the relevant versions of (27) and (28) has to do with their tolerance of adverbial construal of unlikely.) 
The complement of with in these absolutive constructions is arguably no larger than a small clause (see Beukema \& Hoekstra 1984). Since there is no IP projected in the complement of with, the idiom chunk or there is not in a structural subject position.

All these observations suggest that the empirical generalisation underlying the idiom chunk and there facts reviewed for raising-to-object constructions should make reference to the contrast between structural subject positions and 'other' subject positions:

(31) Idiom chunk subjects and there must occupy a structural subject position.

This generalisation is not counterexemplified by the grammaticality of sentences such as (32) (cf. Gee 1977, 468, Rothstein 2004, 51): the fact that sentential negation is possible in the bare-infinitival complement of causative and perception verbs (as shown in (33)) tells us - on the standard assumption that sentential negation requires the presence of $\mathrm{T}$ (Zanuttini 1997) - that this complement must be as large as IP.

(32) a. they made there be no reason to suspect Mary

b. I've never seen there be so many complaints from students before

c. John saw the shit hit the fan

(33) a. this made her not want to do it

b. that was the only time when I saw her not do anything

For 'expletive' there, the traditional approach in the generative framework has an easy time understanding the generalisation in (31): there is inserted in a structural subject position whenever no noun phrase is placed in that position, to satisfy the Extended Projection Principle. The classic EPP is a constraint specifically applying to the structural subject position: in languages subject to the EPP, SpecIP must be filled. An EPP-based approach does not immediately shed light, however, on the question of why idiom chunk subjects can occur only in a structural subject position: there is no sense in which idiom chunks are inserted in SpecIP specifically with a view towards satisfying the EPP. So how come idiom chunk subjects behave just like 'expletive' there with regard to the generalisation in (31)?

I believe an important clue towards an answer to this question comes from the following observations about differences between ECM constructions with consider, on the one hand, and their counterparts with regard as and make out, on the other. Consider first the triple in (34). For (34a), Hornstein $(1995,76)$ points out that inclusion of to be allows the universal 
quantifier that serves as the subject of the embedded predicate to take scope over the existential matrix subject, whereas such inverse scope is unavailable when to be is absent. The examples in $(34 \mathrm{~b}, \mathrm{c})$ contrast with the one in (34a) in that the presence or absence of the copula (being in (34b), to be in (34c)) has no effect on the scope of the universal QP relative to the matrix subject: no matter whether the copula is included or not, an inverse scope reading is unavailable in these sentences.

(34) a. someone considers every Congressman (to be) a liar without to be: $\exists>\forall \quad * \forall>\exists \quad$ with to be: $\exists>\forall \quad \forall>\exists$

b. someone regards every Congressman as (being) a liar

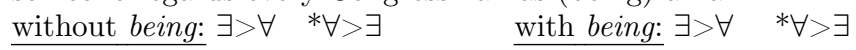

c. someone made every Congressman out (to be) a liar without to be: $\exists>\forall \quad * \forall>\exists \quad$ with to be: $\exists>\forall \quad * \forall>\exists$

Let us examine next the examples in (35), featuring a picture-noun phrase which contains a reflexive as the subject of the embedded predicate. In (35a), the reflexive herself has little difficulty being linked to Mary: the to-infinitive embedded under consider behaves just like the finite clause pictures of herself are a nuisance to Mary, which likewise shows an anaphor connectivity effect. In the regard as and make out examples in (35b,c), by contrast, it is much harder to get herself anteceded by Mary. This is not because herself cannot be bound at all when occurring as the lower subject of regard as and make out constructions: Mary regards pictures of herself as being a nuisance and Mary made pictures of herself out to be a nuisance are fine.

(35) a. they consider pictures of herself to be a nuisance to Mary

b. ? they regard pictures of herself as being a nuisance to Mary

c. ?hey made pictures of herself out to be a nuisance to Mary

For an inverse scope reading to arise for (34b,c), every Congressman would have to undergo QR above the subject, which it apparently cannot. In this respect, $(34 \mathrm{~b}, \mathrm{c})$ behave like the version of $(34 \mathrm{a})$ lacking to be, where $\mathrm{QR}$ of every Congressman is also impossible. The scope of the universal QP is effectively confined to its surface position; it cannot be altered at LF. The binding of herself in (35a) is standardly dealt with via LF 'reconstruction' of the picture-noun phrase below the experiencer Mary (Belletti \& Rizzi 1988). Apparently, this LF operation also fails for the subject of the lower predicate in the regard as and make out constructions in (35b,c), which differs from the lower subject in (35a) in not occupying a structural subject position. 
Let us lay the conclusion emerging from (34) and (35) down as follows:

(36) A subject can undergo an LF operation only if it occupies a structural subject position.

I will return to this generalisation in section 5, and derive it from the theory. For now, it will do as stated. We can link the generalisation in (31) up to (36) if idiom chunk subjects and 'expletive' there must be the target of some LF operation.

For idiom chunks, this is precisely what Chomsky (1995) concludes in his discussion of idioms and constituency. Chomsky argues that in order for a string such as advantage was taken of her to be interpretable as an idiom, take and advantage (which together form the idiom) must form a unit at LF. ${ }^{9}$ This can be achieved by reconstructing advantage into the complement of take via an LF operation. ${ }^{10}$ By (36), LF operations can apply to a subject only if it occupies a structural subject position (SpecIP). The subject of the lower predicate in regard as and make out constructions is not in a structural subject position, hence fails to undergo reconstruction.

For there, the standard Chomskian approach has long been that it needs to be replaced by its associate in order for the sentence to respect the Principle of Full Interpretation. ${ }^{11}$ Expletive replacement is an LF operation that targets there. By (36), such an operation can only be successful if there finds itself in a structural subject position. In consider + to-infinitive constructions, this is indeed the case. But in regard as and make out constructions, it is not.

${ }^{9}$ If idioms are to form a unit at some level of representation, LF is clearly the only option. Neither storing idioms as units in the pre-syntactic lexicon nor forcing them to be units at D-structure is feasible for the entire range of idiomatic expressions. This is particularly clear for expressions that are idiomatic only as transforms, such as you have no leg to stand on (cf. you stand on no leg, which is not idiomatic) or we have our work cut out for us (cf. we have cut our work out for us, which also does not support an idiomatic interpretation).

${ }^{10}$ For idiom chunk subjects of copy raising and tough-movement constructions (advantage seems like it has been taken of her; advantage is easy to take of her), which I argue involve base-generation of the subject in the matrix clause, this requires assuming that a subject of a predicate defined by a predicate variable can be reconstructed into the position of the trace of the predicate variable in the subordinate clause.

${ }^{11}$ Note that the notion of 'expletive replacement' per se is not tied to any particular outlook on the way and place in which there is merged into the structure: we can treat there as a subject of predication, à la Williams (1994; 2006) (as embraced above), and at the same time declare it subject to the requirement that it be replaced at LF on account of its 'unbearable lightness'. There is no contradiction here. 
This now accounts for the ill-formedness of the examples in (25b,c) and (26b,c), above. Of course, promoting the idiom chunk or there to the matrix structural subject position, as in their passive counterparts in $\left(25^{\prime} \mathrm{b}, \mathrm{c}\right)$ and $\left(26^{\prime} \mathrm{b}, \mathrm{c}\right)$, erases the ungrammaticality completely: the idiom chunk or there is now in SpecIP and eligible for manipulation at LF.

Finally, we are in a position to go back to the very beginning of this section, where I mentioned the fact that idiom chunks and there do not occur in cases of copy raising to object: recall (23) and (24). Now that (36) has handed us a perspective on why $(25 \mathrm{~b}, \mathrm{c})$ and $(26 \mathrm{~b}, \mathrm{c})$ are ungrammatical, the ill-formedness of (23) and (24) is directly expected given the proposal in (14) regarding the syntax of copy raising to object. The constituent to the immediate left of like is the subject of a small clause (RP) - a subject, but not the occupant of a structural subject position (SpecIP). Because the pre-like constituent is not a structural subject, it cannot be an idiom chunk or there: idiom chunks and there are the obligatory targets of LF operations; but (36) states that subjects that are not in a structural subject position cannot be targeted by an LF operation. ${ }^{12}$

We also predict that in cases of copy raising to object, we should find that Q-scope interaction between the accusative and the matrix nominative subject will be very difficult, on a par with what we found for $(34 \mathrm{~b}, \mathrm{c})$, above. This seems correct: for all of the sentences in $\left(34^{\prime}\right)$ (the copy raising counterparts to the original examples), wide scope for the universal quantifier is very hard to obtain.

$\left(34^{\prime}\right)$ a. someone considers every Congressman like he's a liar

b. someone regards every Congressman like he's a liar

c. someone made every Congressman out like he's a liar

Whether this is due to the fact that every Congressman in $\left(34^{\prime}\right)$ is not in a structural subject position or to the fact that it binds an overt resumptive pronoun in a subordinate finite clause is impossible to determine for English. The Japanese case of hyperraising to object discovered by Kuno (1976) (which does not feature an overt resumptive) may prove illuminating in this connection: recall that for (4c) Kuno reports that it supports an inverse scope reading with minna-o 'all-ACC'. It may be that thanks to the fact that it binds a silent resumptive in a structural subject position, minna-o can 'count' as a structural subject and undergo QR. It may also

12 In light of $(25 / 26)$ vs $\left(25^{\prime} / 26^{\prime}\right)$, we might expect (23) and (24) to be fixed by passivisation, $\grave{a}$ la (10). Testing this is hard: copy raising is typical of colloquial speech while passivisation of (23)-(24) is more elevated in style. 
be that in Japanese, accusative noun phrases in general are (weakly) able to take scope over the nominative subject even when they are subjects of small clauses. This is a matter I must leave open here.

\section{The distribution of ECM and overt raising to object}

In the approach to the idiom and there facts in ECM constructions presented in the previous section, it is important that the accusative subject of a clausal predicate is sometimes in a structural subject position (SpecIP) and sometimes not. This raises the question of how the theory ensures where the accusative subject is located. In this section and the next, I unfold a perspective on the analysis of ECM constructions that clarifies the role played in this by raising to object.

There is an influential proposal on the market (championed by Postal 1974, and picked up in the principles-and-parameters era by Pesetsky 1989; Johnson 1991; Bošković 1997, i.a.) to the effect that ECM involves overt raising to a structural position in the matrix clause. On this approach, all ECM subjects are matrix objects - not in a thematic sense, but in the sense that they are in the same structural position that 'ordinary' objects of transitive verbs find themselves in. If this is correct, all ECM subjects should behave alike. Postal (1974) presents an impressive array of facts to show that there are indeed important ways in which ECM subjects of various stripes exhibit highly similar behaviour. But as we discovered in the previous section (and as Postal himself is aware), there are also significant differences among ECM subjects.

In the approach to the restrictions on idiom chunks and there presented in section 3, reference to occupancy of a structural subject position is of paramount importance: only those ECM subjects that are occupants of a structural subject position are accessible to LF operations. For the subject of the lower predicate in constructions with regard as, make out and and for copy raising to object constructions, overt raising to object would make no difference to the analysis presented above. For garden-variety ECM constructions featuring consider-type verbs with a to-infinitival complement, applying overt raising to object to the subject of the infinitival clause would also be harmless in the vast majority of cases. But there are three types of ECM sentences for which the discussion in section 3 leads us to conclude that the subject of the to-infinitive under consider-type verbs is not raised into an object position in the matrix clause: sentences such as (25a) and (26a), and the inverse-scope version of (34a) with to be included in it: 
(25a) they consider advantage to have been taken of her

(26a) they consider there to be a problem with the analysis

(34a) someone considers every Congressman (to be) a liar without to be: $\exists>\forall \quad * \forall>\exists \quad$ with to be: $\exists>\forall \quad \forall>\exists$

For these three types of sentences, the logic of (36) compels us to locate the subject of the to-infinitival clause in the SpecIP position of that clause. Raising this subject into an object position in the matrix clause would cause it to no longer occupy a structural subject position by the end of the overt-syntactic derivation. That would forfeit the opportunity for some LF operation to target the ECM subject - and that, in turn, would make it impossible for the idiom chunk to be reconstructed below taken, for there to undergo expletive replacement, and for every Congressman to take wide scope vis-à-vis the matrix subject.

So if the descriptive generalisation in (36) is correct, it is precisely the cases for which we want the ECM subject to be the surface specifier of the IP embedded under the matrix verb which should NOT evince evidence for overt-syntactic raising to object. By far the clearest such evidence comes from placement of the ECM subject vis-à-vis matrix-level adverbial material, as in the sentences in (37) (from Kayne 1985 and Postal 1974; see also Pesetsky 1989 and Johnson 1991):

(37) a. I have believed Gary for a long time now to be a liar

b. I have found Bob recently to be morose

For the particular sentences in (37), the discussion in section 3 places nothing in the way of a raising-to-object analysis. But for (25a), (26a) and inverse-scope (34a), this discussion makes a clear prediction: since these sentences force the application of an LF operation to the ECM subject, and since only those subjects that are the occupants of a structural subject position are eligible targets for LF operations (recall (36)), we expect that (25a) and (26a) will become ungrammatical once the idiom chunk or there is placed to the left of a matrix-level adverbial modifier, and that placement of every Congressman in (34a) in such a position should make the widescope reading for this QP unavailable. Testing this prediction requires some changes to the original examples. The relevant cases are in (38):

(38) a. *they have believed the shit for a long time now to soon be hitting the fan

b. *they have believed there for a long time now to be a problem with the analysis

c. someone has considered every Congressman for a long time now to be a liar $\exists>\forall \quad * \forall>\exists$ 
Of these, the a- and b-sentences are clearly degraded. And while (38c) is of course well-formed, it does not seem to sport an inverse-scope interpretation. The prediction is thus confirmed. ${ }^{13}$

This prediction ties in with the plausible assumption that raising to object is structurally analogous to object shift (of the Scandinavian type) and short scrambling (of the Dutch and German type). ${ }^{14}$ On this assumption, a subject raised to object ends up being interpreted just like shifted or scrambled objects. It is well known for both object shift and scrambling of an object (for key references, see Diesing \& Jelinek 1993 for object shift, and De Hoop 1992 for scrambling) that it is generally best when the object is definite, and that for indefinites (to the extent that they undergo these processes) an interpretive effect is imposed on the object: it is interpreted either specifically or generically. We can translate this specificity/genericity effect as follows: a shifted/scrambled noun phrase is interpreted in its surface position, i.e., cannot be interpreted somewhere else by virtue of the application of some LF operation. The facts in (38) now fall out.

\section{Deriving the accessibility of subjects}

\subsection{The licensing of argumental noun phrases}

From our discussion, it emerges that accusative subjects of embedded clauses do not always raise to an object position in the matrix clause. The generalisation appears to be that accusatives that serve as subjects of IPs are allowed (and sometimes forced) to stay in subject position.

${ }^{13}$ As a reviewer points out, it should also be impossible to place an idiom chunk or there to the left of a matrix-level adverbial in copy raising to object constructions. This is indeed the case: while (i) is fine, (ii) and (iii) are not. It seems unlikely that this could have a register-related cause: unlike passivisation with verbs like consider (recall fn. 12), high placement of an ECM subject as in (i) is not restricted to elevated registers, as far as I am aware. So the ungrammaticality of (ii) and (iii) further confirms the prediction made in the main text.

(i) I have considered Mary for a long time now like she's a good friend

(ii) *I have considered the shit for a long time now like it will soon hit the fan

(iii) *I have considered there for a long time now like there's a problem with the analysis

${ }^{14}$ Johnson (1991) establishes an explicit connection between raising to object and Scandinavian object shift. 
If this is correct, it is straightforwardly derived from a perspective on the licensing of noun phrases that says that SpecIP is a licensed position whereas the subject position of a small clause is not: ${ }^{15}$

(39) An argumental noun phrase must be licensed.

(40) A functional category checking a feature against a noun phrase in its A-specifier position licenses that noun phrase.

Though the subject of a small clause is arguably base-generated in the specifier position of a functional category (the RELATOR of Den Dikken 2006), it does not check any features against the RELATOR. The subject of IP does check at least one feature against I: minimally, the 'EPP feature' is checked in this position. So a subject in SpecIP is in a licensed position, whereas the subject of a small clause is not-for licensing purposes, the subject of a small clause must leave its base-generation site.

Now recall from section 4 that a raised accusative is interpreted in its surface position. In conjunction with the conclusion just reached that the accusative subject of a small clause must raise, this derives the contrast between the two versions of (34a) (Hornstein 1995), repeated here as (41) and (42):

(41) someone considers every Congressman a fool

(42) someone considers every Congressman to be a fool

$$
\begin{aligned}
& \exists>\forall * \forall> \\
& \exists>\forall \quad \forall>\exists
\end{aligned}
$$

The subject of the small clause in (41) is not licensed to stay in the smallclause subject position (an unlicensed position), and must undergo raising to object, which, as we saw in section 4, freezes its scope. Since the landingsite of raising to object (for non-pronominal noun phrases, at least) is a position below the lowest position of the matrix external argument, ${ }^{16}$ no scope interaction between the matrix subject and the embedded subject is possible in (41). The subject of the infinitival clause in (42), by contrast, is licensed to stay in the embedded SpecIP, which allows every Congressman to be manipulated by LF operations, including Quantifier Raising to a

${ }^{15}$ The discussion to follow is based primarily on Den Dikken's (2018, chapter 5) A-SLiP, the licensing condition on A-specifiers, though the text here uncouples the licensing condition from case.

${ }^{16}$ Johnson (1991) takes the position of (non-pronominal) shifted objects to be SpecVP (see also Den Dikken 2018). In Den Dikken (2017a), an aspectual projection between $v$ and VP is implicated. 
position in the matrix clause in which scope interaction with the matrix subject is possible.

Let me make it explicit that it is not being argued here that a constituent is accessible to LF operations if and only if it is in a licensed position. The SpecIP position is a licensed position whose occupant can serve as input to operations at LF; but the object shift position, while being a licensed position, precludes the raised accusative noun phrase from undergoing LF operations: object shift 'freezes' the accusative. The ECM subject of an infinitival clause in principle has the option of undergoing raising or staying in SpecIP; but when the accusative needs access to an LF operation, forgoing raising is the only option. The ECM subject of a small clause, on the other hand, has no choice but to raise, for licensing reasons - and because of the fact that the position it must raise to is 'frozen', the accusative is denied access to LF operations.

With respect to the distribution of object shift, this paper thus lands on the side of Lasnik (2001) and especially Hong and Lasnik (2010), who argue that object shift is obligatory out of small clauses but optional out of ECM infinitivals. ${ }^{17}$ The present discussion adds to this conclusion a connection with LF accessibility: because of its compulsion to raise and because of the 'frozenness' of the object shift position, the accusative subject of a complement small clause is inaccessible to LF operations.

\subsection{A link with the subject restriction on tough movement}

The hypothesis that the subject position of a small clause is an unlicensed position also awards us a prediction regarding the distribution of tough-movement. In Den Dikken (2018, chapter 5), it is argued that a null

${ }^{17}$ Note that there is no difference between the subject of a small clause and that of a to-infinitive when it comes to subextraction, which fails regardless (see Postal 1974, 195):

(i) a. *who do you consider [a picture of ec] indecent?

b. *who do you consider [a picture of ec] to be indecent?

(ii) a. *who did they prove [a memo about ec] inaccurate?

b. *who did they prove [a memo about $e c]$ to be inaccurate?

Here, the dictum 'once a subject, always a subject' applies: a subject is merged as a separate, closed-off unit in a specifier position; nothing can ever take a subpart of a subject out of a subject, no matter where the subject is placed later in the derivation. For objects this is different: even when shifted, they can still bind a copy in a complement position, which is accessible to the establishment of $\bar{A}$-dependencies. 
operator (PRO) is not allowed to be in a licensed position at any point in the derivation: PRO is an unlicensed argument, by definition. ${ }^{18}$

Given this and the fact that SpecIP is always a licensed position, we predict that null operators should never be allowed to be or have been in SpecIP. On the other hand, the subject position of a small clause, an unlicensed position, should be a fine launching site for null operators. This prediction is borne out, as shown by Postal's $(1974,194)$ examples in (43) and (44):

(43) a. Jones is hard to consider competent

b. *Jones is hard to consider to be competent

(44) a. Melvin will be easy to prove guilty

b. ${ }^{*}$ Melvin will be easy to prove to be guilty

For the a-examples, an opportunity presents itself for a null operator because the specifier position of the small clause is an unlicensed position. For the b-examples, by contrast, a null operator stands no chance: SpecIP of the infinitival clause is a licensed position, and the derived object position in the matrix clause is also a licensed position.

\subsection{Summary}

The complex cocktail presented by the similarities and differences between subjects of complement small clauses and subjects of to-infinitival complement clauses reviewed in the preceding paragraphs thus falls out from (45). Both idiom chunk subjects of passivised idioms and the 'expletive' there must be subjected to an operation at LF (reconstruction, expletive replacement); as subjects of a small clause in the verb's complement, they would be forced to undergo overt object shift, which in turn would cause a violation of the Principle of Full Interpretation.

(45) a. overt raising to object exists in English

b. overt raising to object makes the accusative noun phrase inaccessible to LF operations

c. overt object shift serves to license the subject of a verb's small-clause complement

18 This is the equivalent of the PRO Theorem in early principles-and-parameters theory. Unlike in the case of the PRO Theorem, the statement that PRO is an unlicensed argument does not fall out as a theorem of the binding theory. This statement is now part of the lexical definition of PRO. 
d. overt object shift is not required for the subject of a verb's to-infinitival complement, which can be licensed in SpecIP ${ }^{19}$

e. a null operator (PRO) is an unlicensed argument

The account leads us to endorse the existence of overt object shift in English, in line with Postal (1974), Pesetsky (1989), Johnson (1991) and Bošković (1997) - though unlike these authors, but in line with Hong \& Lasnik (2010), it makes object shift of accusative subjects of predication obligatory only for small clause subjects, not for subjects of full IPs. ${ }^{20}$

\section{A note on Hungarian long $\bar{A}$-dependencies involving subjects}

In Den Dikken (2018, chapter 4), I present a detailed account of the five different ways in which speakers of Hungarian can render an English long subject wh-question such as (46). Of these five patterns, two are not of interest to us in this paper (viz., the $w h$-scope marking and oblique prolepsis versions). But the remaining three are very much worth placing side by side in the context of the foregoing discussion of copy raising and hyperraising to object. The three patterns are illustrated in (47).

${ }^{19}$ One might ask why object shift would ever occur in the case of the subject of a to-infinitive: if the purpose of object shift is licensing, and if the subject of a to-infinitive is licensable in SpecIP, there would seem to be no point in performing object shift on the subject of a to-infinitival clause. Empirically, there can be little doubt that object shift can apply here, as (37) showed; as a matter of fact, placing Gary in (37a) or Bob in (37b) to the immediate left of to would make these sentences ungrammatical - an 'adjacency effect' that may suggest that licensing of the subject of the to-infinitive in SpecIP fails under the intervention of a matrix adverbial. If so, we might expect that Gary in (37a) and Bob in (37b) are never in the SpecIP position of the to-infinitive: if this is an unlicensed position here, it would make sense for these noun phrases to be launched into the object shift position straight from the thematic subject position of the embedded clause. The distribution of floating quantifiers could potentially shed light on the question of whether object shift transits through the embedded SpecIP. The sentences in (ia,b) with all or both to the right of to are evidently grammatical; those with all/both between the matrix adverb and to seem degraded, but the degree of deviance may not be sufficiently strong to indicate that no stop-over in the embedded SpecIP is made in to-infinitival ECM constructions in which overt raising to object is demonstrably taking place.

(i) a. I have believed these people for a long time now $\left\langle{ }^{?}\right.$ both $\rangle$ to $\langle$ both $\rangle$ be liars

b. I have found these people recently $\langle$ ? all $\rangle$ to $\langle a l l\rangle$ be morose

${ }^{20}$ Bošković (1997) also uses the selective optionality of object shift, making it optional for objects but obligatory for accusative subjects of small and infinitival clausal complements alike. But this does not make the right cut. 
(46) how many girls do you think are coming to the party?

(47) a. (?)?hány lány gondol-od, hogy jön(*-nek) a buliba? (Hungarian) how.many girl(NOM) think-2SG.DEF that come-*3PL the party.to

b. $\quad \checkmark / ?$ ? hány lány-t gondol-sz, hogy jön-nek a buliba? how.many girl-ACC think-2SG.INDEF that come-3PL the party.to

c. hány lány-t gondol-sz, hogy jön a buliba? how.many girl-ACC think-2SG.INDEF that come.3SG the party.to all: 'how many girls do you think are coming to the party?'

Of the sentences in (47), the first is a simple case of long-distance whfronting, directly on a par with English (46). The wh-phrase has the nominative case that is assigned to it in the embedded finite clause. The clause is transparent for long wh-movement of its subject thanks to the fact that it is engaged in an Agree relationship for the feature [+definite] with the matrix verb.

More interesting are the examples in (47b) (which gives rise to speaker variation) and (47c). Throughout (47), the wh-phrase hány lány 'how many girl' is formally singular, so in (47b) it cannot be the case that this noun phrase is lauched from the subject position of the embedded clause: such would deliver singular jön, as in (47a). In Den Dikken (2018, chapter 4) it is argued that (47c), with its plural agreement on the lower verb and upstairs indefinite agreement with the accusative wh-phrase hány lányt, is a case of resumptive prolepsis: the subject of the lower clause is a silent pronoun, pro. In the structure in (48) (taken from Den Dikken 2018), the wh-phrase originates in a position in the matrix clause in which it is the subject of the $\mathrm{CP}$ in the complement of $\mathrm{V}$, which contains a pronominal predicate variable $\left(\right.$ pro $\left._{3 \mathrm{PL}}\right){ }^{21}$ If this analysis is correct, this makes $(47 \mathrm{~b})$ the counterpart to 'copy raising to object' in the $\bar{A}$-domain.

(48) [FocP hány lányt [F [TP pro $_{2 \mathrm{SG}}\left[\mathrm{T}\left[{ }_{v \mathrm{P}} v[\mathrm{VP} y\right.\right.$ [V [CP hogy pro $\left.\left.\left.\left.\left.\left.\left.3 \mathrm{PL} \ldots]\right]\right]\right]\right]\right]\right]\right]$

In (47c), hány lányt 'how many girl.ACC' again surfaces with accusative case, and serves as the Agree-goal for the matrix verb. But unlike in (47b), the verb in the embedded clause bears singular inflection, indicating that

${ }^{21}$ Den Dikken (2018) takes V to be the RELATOR of the predication relation between the $\mathrm{CP}$ and the proleptic object in SpecVP, with V and CP forming a complex predicate. Alternatively, the predication relation can be represented entirely inside the complement of V, with V taking a small clause (RP) as its complement. For our purposes here, this will be immaterial. 
the $w h$-phrase is itself the subject of the lower clause. This suggests a parallel with 'hyperraising to object': the wh-phrase literally raises out of the embedded finite clause and lands in the matrix accusative object position. There are several considerations, however, that plead cogently against the idea that literal movement of hány lány out of the lower clause and into the higher clause is involved in the derivation of (47c). Empirically, that there is no direct movement dependency across the embedded CP in the syntax of $(47 \mathrm{c})$ is confirmed by the fact that while (47a) evinces a clear wh-island effect (see (49a)), neither (47b) nor (47c) does, as shown by the grammaticality of (49b) (for speakers who accept (47b)) and (47c). That (49b) is grammatical is of course expected in light of the resumptive prolepsis analysis in (48). The ungrammaticality of (49c) tells us that there can be no $\bar{A}$-movement of hány lány out of the embedded CP. Though this could still leave open the possibility of A-movement (perhaps unhindered by $w h$-islands), a stumbling block for any movement dependency crossing $\mathrm{CP}$ in (47c) is the fact that the matrix verb does not establish an Agree relation with the embedded clause. This causes CP to be an absolute island for movement dependencies across its borders (see Den Dikken 2018 for background discussion and references to the relevant literature).

(49) a. *hány lány kérdezted, hogy mikor jött el? how.many girl(NOM) ask.PST.2SG.DEF that when came PV

b. hány lány-t kérdeztél, hogy mikor jött-ek el? how.many girl-ACC ask.PST.2SG.INDEF that when came-3PL PV

c. hány lány-t kérdeztél, hogy mikor jött el? how.many girl-ACC ask.PST.2SG.INDEF that when came.3SG PV

So although $(47 \mathrm{c})$ might at first blush seem to be a potential candidate for an analysis in terms of literal hyperraising out of the subject position of the embedded finite clause and into the accusative object position in the matrix clause, it turns out upon closer examination that no movement dependency exists between the matrix object hány lányt 'how many girl.ACC' and the subject position of the subordinate clause. ${ }^{22}$ There is, to be sure, a dependency between the two - Den Dikken (2018, chapter 4, q.v.

${ }^{22}$ It seems to me likely that the same conclusion, mutatis mutandis, will turn out to hold for English constructions of the type in (i) (of which the relevant portions are in boldface), recently discussed under the label 'wh-raising' (and analysed as cases of actual movement out of the embedded clause) by Danckaert and Haegeman (2017) - who themselves note the probable link with (ii), which is like Hungarian (47c). All of the 'raising' constructions in $(47 \mathrm{~b}, \mathrm{c})$, (i) and (ii) are generally grammatical only with 
for details irrelevant here) analyses the lower subject as a dropped topic identified by the matrix object. But neither in the Hungarian examples nor in the ones reviewed earlier in this paper does 'copy raising to object' or 'hyperraising to object' exist as a case of literal movement out of a finite subordinate clause into the matrix clause. What (47b) and (47c) have in common is that the embedded CP serves as the predicate of the matrix wh-dependency, and functions as such thanks to the fact that it contains a predicate variable (in the sense of Williams 1980).

\section{Concluding remarks}

\subsection{The empirical picture in a nutshell}

In this paper, I have juxtaposed three different patterns of 'raising constructions', illustrated in (50i-iii) using English words (though English does not actually realise all nine options):

(50) i. a. he seems to be smart

b. he seems that is smart

c. he seems like he is smart

ii. a. they consider him to be smart

b. they consider him that is smart

c. they consider him like he is smart

iii. a. who do you think is smart?

b. who do you think that is smart?

c. who do you think that he is smart?

In Den Dikken (2017c), the examples in (50i) (whose a- and c-cases occur in English, while the b-case is found, for instance, in Brazilian Portuguese) were in focus. The present paper concentrated primarily on the triple in (50ii) (with English again instantiating the a- and c-examples, and Japanese giving rise to the b-case), and showed it is directly related to

$\bar{A}$-moved subjects of predication, for reasons that are not very clearly understood at this time (but see Den Dikken 2018 for relevant remarks on (47c)).

(i) a. McDonald's has also seen an increase in the standard of hygiene across restaurants which is felt is attributable to the fact that the programme is now specifically about McDonald's restaurants

b. a recording was also made of each School and was then used to transcribe the minutes and any quotes which were felt were relevant to the process

(ii) this is the candidate whom we expect will win the competition 
(50i) and arguably also to the wh-examples in (50iii) (with special reference to Hungarian).

\subsection{On the involvement of movement in raising and copy raising}

For the a-examples in (50), analyses in terms of movement are standard, and there is no particular reason to abandon such an analysis for these sentences. But applying a movement analysis to the b- and c-sentences is untenable, for each of the three subdomains. Both 'hyperraising' and 'copy raising' involve base-generation in the matrix clause cum predication. ${ }^{23}$

Raising qua movement, as found in sentences such as (50ia), can affect nominal as well as non-nominal constituents (in particular, clauses, and, in locative inversion constructions, PPs). We see this in (51). Moreover, raising qua movement is possible with 'expletive' there and idiom chunks, as shown in (52).

(51) a. an interesting claim about copy raising seems to have been made in that paper

b. in that paper seems to have been made an interesting claim about copy raising

c. [that copy raising involves movement] seems to have been claimed in that paper

(52) a. there seems to be no simple solution to this problem

b. advantage seems to have been taken of the situation

Another fact about raising qua movement is that it can target positions other than the subject position of IP. (53a) illustrates this for the case of a to-less infinitival complement to causative make, and (53b) shows that the subject position of an adjectival small clause can serve as the landingsite of raising. On a number of analyses of the double object construction (Larson 1988; Den Dikken 1995), (53c) is another example of raising, once again clearly not targeting the subject position of IP.

(53) a. he makes this seem easy

b. he considers this likely to happen

c. he gave her a book

${ }^{23}$ Luigi Rizzi (p.c.) points out that pseudorelatives (such as French j'ai vu Jean qui embrassait Marie '(lit.) I saw Jean who kissed Marie, i.e., I saw Jean kiss Marie') are plausibly treated in these terms as well, with Jean as the subject of a complement small clause whose predicate is a $\mathrm{CP}$ with an operator-variable dependency inside it. 
Though copy raising, as we have seen in this paper, can target a smallclause subject position (as in she regards John like he's an idiot), it differs notably from true raising with respect to the set of possible undergoers. Postal $(2004,46)$ notes that there is no copy raising with locative inversion:

(54) a. in the woods (there) are fighting two wild boars

b. *in the woods sounds like there are fighting two wild boars

(55) *in that paper seems like there has been made an interesting claim about copy raising

The ungrammaticality of (54b) and (55) furnishes a strong argument against a movement-based analysis of copy raising. On such an analysis, there is really no obvious answer to the question of why these sentences fail. As (54a) shows, locative inversion in constructions with an indefinite postverbal subject is perfectly compatible with there, so there should be able to serve as the 'copy pronoun' spelling out the intermediate position in the chain of movement of the locative PP that is realised in the matrix subject position. The predication-based approach taken in this paper and in Den Dikken (2018), on the other hand, explains the ungrammaticality of (54b) and (55) immediately. The PPs in the matrix clause are predicates, not subjects of predication. There is no way for these predicative PPs to be related to the finite clause following like: they cannot serve as the subject of predication, nor can they be predicated of the finite clause. (54b) and (55) are thus uninterpretable on the predicational approach, which explains their deviance. ${ }^{24}$

\subsection{The distribution of overt raising to object}

With 'expletive' there and idiom chunks, the output of copy raising is good only in cases in which a SpecIP position is targeted:

(56) a. there seems $\left\{{ }^{\vee}\right.$ to be $/{ }^{`}$ like there is $\}$ no simple solution to this problem

b. they consider there $\left\{{ }^{\sqrt{ } \text { to }}\right.$ be $/{ }^{*}$ like there is $\}$ no simple solution to this problem

(57) a. advantage seems $\left\{{ }^{\vee}\right.$ to have/ $/{ }^{\top}$ like it has $\}$ been taken of the situation

b. they consider advantage $\left\{{ }^{\top}\right.$ to have $/ *$ like it has $\}$ been taken of the situation

${ }^{24}$ In fn. 5, I pointed out that Yuan (2016) argues for hyperraising in Kikuyu that it must involve movement out of the lower clause. In light of the discussion in this paragraph, it will be interesting to investigate whether Kikuyu allows hyperraising under locative inversion. I have no access to the relevant data. 
These restrictions on 'expletive' there and idiom chunks are not specific to the copy raising construction: we find them also in regard as and make out constructions, as I showed in (25) and (26) (cf. Postal 1974, 242 and Kayne 1985, 114); similar examples are given here as (58) and (59):

(58) a. they consider there to be no simple solution to this problem

b. *they regard there as being no simple solution to this problem

c. *they made there out to be no simple solution to this problem

(59) a. they consider advantage to have been taken of the situation

b. *they regard advantage as having been taken of the situation

c. *they made advantage out to have been taken of the situation

I argued in sections 4 and 5 that these facts are instructive regarding the distribution of raising to object. Overt raising to object exists in English, and is the equivalent of object shift and short scrambling elsewhere in Germanic, as argued previously by Pesetsky (1989) and especially Johnson (1991). More specifically, this paper argues - in agreement with Hong and Lasnik (2010) - that overt object shift is required, for licensing purposes, for small-clause subjects, but that the accusative subject of a verb's to-infinitival complement can be licensed in SpecIP, so overt object shift is not required in this case (though recall fn. 19 on the matter of adjacency).

Thus, this paper endorses the existence of overt object shift in English, but it also shows that there is an important difference between small-clause subjects and subjects of ECM-infinitives with respect to the obligatoriness of object shift: object shift is obligatory for the former but not for the latter, thanks to the fact that a subject can be licensed in SpecIP.

\section{Acknowledgements}

Portions of the research done for this paper were financially supported by Hungarian Scientific Research Fund (OTKA) grant \#84217, to Balázs Surányi, which is very gratefully acknowledged. I would like to thank Kriszta Szécsényi and the participants in the seminar 'On raising and NP-movement'/'Az emelő szerkezetek és az NP mozgatás' that Kriszta and I co-taught at the Department of English Linguistics at Eötvös Loránd University in Budapest (February-May 2017) for their inspiring feedback. Thanks are due as well to two anonymous reviewers and to the audience at the 19th Annual International Conference of the English Department (AICED19) of the University of Bucharest (June 2017) for their highly relevant comments and questions. Finally, I express my heartfelt gratitude to George Soros, maecenas of science, sanity and civil society; ceterum censeo orbanum esse delendum. 


\section{References}

Aarts, Bas. 1992. Small clauses in English: The nonverbal types. Berlin \& New York: Mouton de Gruyter.

Asudeh, Ash and Ida Toivonen. 2012. Copy raising and perception. Natural Language \& Linguistic Theory 30. 321-380.

Belletti, Adriana and Luigi Rizzi. 1988. Psych-verbs and $\theta$ theory. Natural Language \& Linguistic Theory 6. 291-352.

Beukema, Frits and Teun Hoekstra. 1984. Extraction from with-constructions. Linguistic Inquiry 15. 689-698.

Bošković, Željko. 1997. The syntax of nonfinite complementation: An economy approach. Cambridge: Cambridge University Press.

Carlson, Greg N. 1977. Reference to kinds in English. Doctoral dissertation. University of Massachussetts at Amherst. Megjelent 1980-ban Garland Press, New York.

Chomsky, Noam. 1981. Lectures on government and binding. Dordrecht: Foris.

Chomsky, Noam. 1995. The minimalist program. Cambridge, MA: MIT Press.

Danckaert, Lieven and Liliane Haegeman. 2017. Syntacticizing blends: The case of English wh-raising. In O. Fernández-Soriano, E. Castroviejo and I. Pérez-Jiménez (eds.) Boundaries, phases and interfaces: Case studies in honor of Violeta Demonte. Amsterdam \& Philadelphia: John Benjamins. 28-46.

Diesing, Molly and Eloise Jelinek. 1993. The syntax and semantics of object shift. Working Papers in Scandinavian Syntax 51. 1-54.

Dikken, Marcel den. 1995. Particles: On the syntax of verb-particle, triadic and causative constructions. New York: Oxford University Press.

Dikken, Marcel den. 2006. Relators and linkers: The syntax of predication, predicate inversion, and the copula. Cambridge, MA: MIT Press.

Dikken, Marcel den. 2017a. Differential object marking and the structure of transitive clauses. In G. Bellucci, L. Franco and P. Lorusso (eds.) Linguistic variation: Structure and interpretation. Berlin \& New York: Mouton de Gruyter.

Dikken, Marcel den. 2017b. Predication in the syntax of hyperraising and copy raising. Acta Linguistica Academica 64. 1-41.

Dikken, Marcel den. 2018. Dependency and directionality. Cambridge: Cambridge University Press.

Ferreira, Marcelo. 2000. Argumentos nulos em português brasileiro [Null arguments in Brazilian Portuguese]. MA Thesis. Universidade Estadual de Campinas.

Ferreira, Marcelo. 2004. Hyperraising and null subjects in Brazilian Portuguese. MIT Working Papers in Linguistics 47. 57-85.

Gee, James Paul. 1977. Comments on the paper by Akmajian. In P. W. Culicover, T. Wasow and A. Akmajian (eds.) Formal syntax. New York: Academic Press. 461-482.

Halpert, Claire. 2016. Raising parameters. In K. min Kim, T. B. Pocholo Umbal, Q. Chan, T. Cheng, K. Finney, M. Katz, S. Nickel-Thompson and L. Shorten (eds.) Proceedings of the 33rd West Coast Conference on Formal Linguistics. Somerville, MA: Cascadilla Press. 186-195.

Hong, Sungshim and Howard Lasnik. 2010. A note on 'Raising to Object' in small clauses and full clauses. Journal of East Asian Linguistics 19. 275-289. 
Hoop, Helen de. 1992. Case configuration and NP interpretation. Doctoral dissertation. University of Groningen.

Horn, Stephen. 2008. Syntax, semantics, and pragmatics of accusative-quotative constructions in Japanese. Doctoral dissertation. The Ohio State University, Columbus.

Hornstein, Norbert. 1995. Logical Form: From GB to Minimalism. Oxford \& Cambridge, MA: Blackwell.

Johnson, Kyle. 1991. Object positions. Natural Language \& Linguistic Theory 9. 577-636.

Kayne, Richard. 1985. Principles of particle constructions. In J. Guéron (ed.) Grammatical representation. Dordrecht: Foris. 101-140.

Kuno, Susumu. 1976. Subject raising. In M. Shibatani (ed.) Syntax and semantics 5: Japanese generative grammar. New York: Academic Press. 17-41.

Larson, Richard. 1988. On the double object construction. Linguistic Inquiry 19. 335-391.

Lasnik, Howard. 2001. Subjects, objects, and the EPP. In W. D. Davies and S. Dubinsky (eds.) Objects and other subjects: Grammatical functions, functional categories and configurationality. Dordrecht: Kluwer. 103-121.

Martins, Ana Maria and Jairo Nunes. 2006. Apparent hyper-raising in Brazilian Portuguese: Agreement with topics across a finite CP. In P. Panagiotidis (ed.) The complementiser phrase: Subjects and wh-dependencies. Oxford: Oxford University Press. 143-163.

Nunes, Jairo. 2008. Inherent case as a licensing condition for A-movement: The case of hyper-raising constructions in Brazilian Portuguese. Journal of Portuguese Linguistics 7. 83-108.

Pesetsky, David. 1989. Language-particular processes and the Earliness Principle. Paper presented at the 12th GLOW Colloquium, Utrecht, April 1989; abstract in GLOW Newsletter.

Pollard, Carl and Ivan A. Sag. 1994. Head-driven Phrase Structure Grammar. Chicago \& Stanford: University of Chicago and CSLI.

Postal, Paul. 1974. On raising: One rule of English grammar and its theoretical implications. Cambridge, MA: MIT Press.

Postal, Paul. 2004. Skeptical linguistic essays. Oxford: Oxford University Press.

Potsdam, Eric and Jeffrey Runner. 2001. Richard returns: Copy raising and its implications. In M. Andronis, C. Ball, H. Elston and S. Neuvel (eds.) CLS37: The main session, Vol. 1. Chicago: Chicago Linguistic Society. 453-468.

Rothstein, Susan. 2004. Predicates and their subjects. Dordrecht: Springer.

Williams, Edwin. 1980. Predication. Linguistic Inquiry 11. 203-238.

Williams, Edwin. 1994. Thematic structure in syntax (Linguistic Inquiry Monograph 23). Cambridge, MA: MIT Press.

Williams, Edwin. 2006. The subject-predicate theory of there. Linguistic Inquiry 37. 648-651.

Yuan, Michelle. 2016. Paper presented at the LSA Annual Meeting in Washington, DC. Subordinate clause types and the left periphery in Kikuyu.

Zanuttini, Raffaella. 1997. Negation and clausal structure: A comparative study of Romance languages. Oxford: Oxford University Press.

Zeller, Jochen. 2006. Raising out of finite CP in Nguni: The case of fanele. Southern African Linguistics and Applied Language Studies 24. 255-275. 